\title{
The year-two effect: Evidence and antecedents for second season success in NCAA division I football
}

\author{
N. David Pifer ${ }^{\mathrm{a}, *}$ and Matt R. Huml ${ }^{\mathrm{b}}$ \\ ${ }^{a}$ Department of Kinesiology and Sport Management, Lubbock, Texas Tech University, TX, USA \\ ${ }^{\mathrm{b}}$ School of Human Services, University of Cincinnati, Cincinnati, OH, USA
}

\begin{abstract}
In recent years, it has become common for media members and other college football affiliates to associate a program's turnaround with the Year-Two Effect, a phenomenon whereby an NCAA Division I football program is expected to make large improvements during a head coach's second season in charge. However, like many of the mass media's sport truisms, this phenomenon has gone untested and unexplored in the broader realm of empirical literature. Given the big business that is modern day college football, where revenues have reached the billions of dollars, and tens of millions are being spent on coaching salaries, bonuses, contract extensions, and buyouts, further examinations into the Year-Two Effect, its causes, and its implications are warranted from both the analytical and economical perspectives. Using two-way fixed effects panel regression models to analyze 11 seasons (2007-17) of data for 114 NCAA Division I Football Bowl Subdivision (FBS) programs, this study found support for the Year-Two Effect's existence, particularly in situations where coaches were replacing a prior coach that had been fired for on-field performance reasons. In addition, teams also tended to significantly improve their recruiting rankings and commit fewer turnovers during a head coach's second season at the helm.
\end{abstract}

Keywords: NCAA football, coaching tenure, second season, improvement, analytics

\section{Introduction}

During the 2017 National Collegiate Athletic Association (NCAA) Division I football season, the University of Georgia's second-year head coach, Kirby Smart, led the Bulldogs to a 13-2 record, a Southeastern Conference (SEC) title, a Rose Bowl victory over No. 2 Oklahoma, and the program's first appearance in a National Championship since 1980. Such achievements were notable because they stood in sharp contrast to Smart's first season in charge, when his Georgia squad went 4-4 in the SEC and 8-5 overall. Following the quick turnaround, Smart was singled out by members of the media for exemplifying what many in the industry refer to as the Year-Two Effect (Emerson, 2017).

\footnotetext{
${ }^{*}$ Corresponding author: N. David Pifer, Kinesiology and Sport Management, Box 43011, Lubbock, TX 79409, USA. Tel.: +1 806 834 2346; E-mail: david.pifer@ttu.edu.
}

The Year-Two Effect can be defined as the expected improvement by an athletic program during a head coach's second season at the helm. In addition to Smart, a number of other head football coaches have been associated with this phenomenon over the years, including Bob Stoops at the University of Oklahoma (7-5 to 13-0 across the 1999-00 seasons) and Bill Snyder at Kansas State University (1-10 to 5-6 across the 1989-90 seasons), to Smart's former mentor, Nick Saban, at the University of Alabama (7-6 to 12-2 across the 2007-08 seasons). Even Smart's predecessor at Georgia, Mark Richt, enjoyed his best season with the Bulldogs during his second season in charge of the program (8-4 to 13-1 across the 2001-02 seasons).

Like many other clichés that have taken up residence in the mass media's archive of generalized assumptions, the Year-Two Effect finds itself recycled and repeated nearly any time a second-year Division I 
football coach manages to find themselves on the positive end of a year-two turnaround. "It [the Year-Two Effect] definitely happens a lot," notes former college football player and current ESPN analyst David Pollack. "It's confidence. It's familiarity with the coach. It's knowing expectations and rules" (Emerson, 2017, para. 6). But is the Year-Two Effect simply taken at face value because a handful of the sport's more prominent coaches were able to improve their programs in season two? Does historical and statistical evidence actually support this assumption, or are the media and the public falling victim to an availability heuristic ${ }^{1}$ of sorts? Furthermore, if the Year-Two Effect is an actual thing, what factors are likely contributing to its existence?

With the NCAA Division I football industry currently responsible for a large portion of the NCAA's more than $\$ 9$ billion in annual revenues, and coaching salaries now reaching into the tens of millions of dollars (Fulks, 2016), it is an appropriate time to examine the merits of the Year-Two Effect and whether or not it offers any practical suggestions to college coaches, administrators, fans, and media members moving forward. Seeing as the answers to these questions might yield valuable insights for researchers and key stakeholders in the college football industry, this study set out to investigate whether or not the Year-Two Effect is supported by statistical evidence. From there, it proceeded to examine those factors that may be driving its existence, and how those involved with the year-to-year projections of college football teams can benefit from this knowledge.

\section{Background}

The context of this study is stationed within intercollegiate athletics, primarily within the NCAA's Division I member institutions. Division I members are informally classified as Power Five or Group of Five institutions. Power Five institutions include member schools within the Big Ten, Big 12, Pac12, Southeastern Conference (SEC), and Atlantic Coast Conference (ACC). The Group of Five includes member schools within Conference USA (C-USA), Mid-American Conference (MAC), Sunbelt Conference, Mountain West Conference (MWC), and American Athletic Conference (AAC). Both classifications fall within the Football Bowl Subdivision $(F B S)$, college football's highest level of competition.

FBS programs, and Power Five institutions in particular, have recently been on the receiving end of increased revenues and greater autonomy in the NCAA legislation process. For example, the SEC recently paid out over $\$ 40$ million to each member school based on revenue generated by the SEC Network, tournament ticket sales, and appearances in football bowl games (Kirshner, 2018). This revenue provided to member schools does not include the revenue each school generates on its own campus for home events or fundraising efforts to cover expenses like scholarships and new facilities (Huml, Pifer, Towle, \& Rode, 2019). The reaction to this significant increase in revenue potential has seen athletic departments spending more than ever before in an attempt to field more successful teams.

In recent financial reports from the NCAA, median expenses increased for FBS schools from \$28.9 million in 2004 to $\$ 66.3$ million in 2015 , an increase of $128 \%$ (Fulks, 2016). Football coaching staffs have been some of the largest benefactors of these rising expenses, as the number of positions available and the salaries for coaches and coordinators have risen dramatically. Scholars have recently identified significantly increased salaries and more lucrative contract incentives within coaching contracts (Fogarty, Soebbing, \& Agyemang, 2015; Hoffer \& Pincin, 2016). Hoffer and Pincin (2016), for example, found that coaching salary increases were outpacing increased expenses connected to student-athletes by more than $750 \%$ since 2006.

The tendency to take college football's rising revenues and apply them to head coaches and their staffs highlights the risk/reward model of college athletics. FBS athletic departments are constantly increasing their expenses in order to maintain or recapture success on the playing field, often with the promise to university leadership of it leading to an increased bottom line. At the forefront of this risk is hiring an expensive head coach in the hopes that they will bring greater success to the program. Therefore, being able to structure contracts and buyout clauses around realistic ideas and expectations for when a program should turn around could prove helpful in this setting. In a similar vein, further knowledge of the potential drivers for rapid success could assist these programs and their coaches in identifying areas of strength and weakness. In these regards, the YearTwo Effect certainly positions itself as a phenomenon in need of further examination for both its relevancy to analytics and the economics of FBS athletic departments. 


\section{Literature review}

A wide-ranging review of the NCAA football coaching literature found rather limited evidence of the Year-Two Effect being directly examined in academic studies. Rather, there existed just a small collection of popular press articles that had examined this phenomenon. Perhaps unsurprisingly, these examinations were more anecdotal in nature and incorporated limited timeframes in their samples. Connelly (2016), for instance, assessed how FBS teams' ratings from 2011 to 2015 - as derived from an analytical model—changed based on the tenure of the head coach. He found that teams with firstyear and third-year head coaches dropped in the ratings by an average of -0.2 and -0.1 adjusted points per game, respectively. Second-year coaches, however, tended to improve by 3.0 adjusted points per game. Even so, when average changes in the ratings were held against the light of both coaching tenure and a team's prior three-year average for those ratings, there appeared to be a pretty clear trend; that is, teams that had suffered from bad performances in the past tended to improve dramatically, regardless of coach year, while those that had been performing at a high level tended to regress before their ratings slightly rebounded in a coach's second season.

In a separate examination, Hokanson (2008) took more of a case analysis approach, compiling a lengthy list of FBS coaches at reputable programs who had enjoyed second-year success and speculating on the reasons for why they were able to experience these jumps in their second seasons. Among the explanations were the new schemes and attitudes instilled by a fresh staff, and the additive effect they had on the playing talent that had carried over from the previous regime. In addition, the suggestion was made that the second season instills a new level of optimism and confidence in a team as it works harder to improve while getting more of its pieces in place. Nonetheless, while these base-level examinations offered some intriguing food for thought, they were neither subjected to the rigors of peer review nor bolstered by analyses that were capable of revealing significant effects.

In terms of peer-reviewed literature that has examined the potential effects of coaching tenure on performance, there exists a subset of studies that have lent insights to this area. One such study was conducted by Dohrn, Lopez, and Reinhardt (2015) to look at leadership succession in NCAA football and the impact it had on FBS teams' financial and athletic performances over one, two, and four-season timeframes. Following a series of regression analyses, it was reported that new coaches positively and significantly impacted the on-field performances of teams over these time periods, as determined by absolute increases in Sagarin ratings, Sagarin ranks, and winning percentages. Second-year improvements, however, were not notably better than those occurring in the first and fourth seasons. However, the results yielded additional insights once all of the programs in the overall sample had been bucketed into smaller samples based on football-related revenue. High-revenue programs, for instance, did not experience significant improvements over any time period when hiring a new coach. In low-revenue programs, the effect was the opposite, as new coaches almost always tended to improve the program over the one, two, and four-season timeframes. In the tier of mid-revenue programs, results indicated the potential existence of a second-year effect, as the year-two improvements following a coaching change showed both the strongest levels of significance and the largest effect sizes of the three timeframes and revenue groups in the sample.

Shedding further light on the relationship between coaching tenure and performance was a study by Maxcy (2013) on FBS coaching and recruiting efficiency. This wide-ranging analysis showed that the replacements for retired or fired coaches performed significantly worse on the field during their first seasons in charge, but that the significance of this effect wore off from the second season onward. A subsequent analysis of the effects that performance in prior seasons had on recruiting lent support to the possibility that improved recruiting efforts were at the source of greater success in year two. Indeed, there was a significant drop-off in a program's recruiting rankings when a new coach was hired to replace a coach who was fired or had moved on, but this effect reversed and showed significant improvements in the second year after a fired coach had been replaced. A more recent study by Huml et al. (2019) provided additional evidence that improved recruiting from a newly hired coach could be at the root of the Year-Two Effect. Looking at the effects that newly renovated or constructed facilities had on programs' year-to-year recruiting rankings in Division I football and basketball, control variables for a coach being in his second season were seen to be significantly related to improvements on the recruitment front. 
The implications that can be drawn from analyses such as these stem from a long line of literature logically linking player recruitment with on-field success. Many of these examinations have looked at simple correlations and one-way relationships between the recruiting rankings furnished by scouting sites such as Rivals, 247sports, and ESPN, and the on-field performances of football programs as measured by wins, winning percentages, associated press (AP) rankings, and other specialized ranking metrics. Herda et al. (2009), for instance, found that various recruiting metrics from Scout and Rivals explained up to $45 \%$ of the variance in teams' Sagarin rankings and win totals the next season. Speaking to the reverse, it was also seen that on-field success in a preceding season explained $51 \%$ of the total variance in teams' recruiting ratings the next year. Caro (2012) echoed these findings, showing that there was a significant and positive correlation between recruiting success, as measured by the average "star" ratings of recruits, and teams' conference winning percentages the next season. This was particularly evident in the Power Five conferences, where successful recruiting in the SEC, Big Ten, and Big 12, helped explain anywhere from $63 \%$ to $80 \%$ of their teams' conference records. Maxcy (2013) also found that football programs' recruiting class rankings from the five previous seasons had significant and positive effects on a team's athletic performance. More recently, Bergman and Logan (2016) looked at the impact that recruits' star ratings had on teams' on-field performances while controlling for school-specific fixed effects. Although the fixed effects marginalized the impact that recruit quality had on team performance, recruits' rankings were still found to be statistically and economically significant. It was estimated, for example, that a fivestar recruit was worth more than $\$ 150,000$ in expected bowl game revenues to a school.

Recruiting, though, is not the only variable aligned with the fortunes of NCAA football coaches and teams. Coaching salaries and team performance, for example, are positively correlated, and when schools change coaches, higher pay is generally associated with improved performance (Colbert \& Eckard, 2015). In looking at the determinants of compensation in the FBS, it was seen that team rankings, lifetime winning percentages, years of experience, and recruiting success were all significantly and positively related to higher pay (Grant, Leadley, \& Zygmont, 2013). In terms of coach retention, a study by Holmes (2011) positioned conference wins, being an alumnus, and a strong record against rival teams as variables that significantly decreased the likelihood of a coach being fired. Interestingly, this same study found that coaches with stronger recent performances, in terms of winning percentages, decreased their chances of dismissal, but coaches with stronger historical performances actually increased their chances of dismissal. Perhaps in these situations it was difficult to overcome the unrealistic standards that had been set from the start. The Year-Two Effect could certainly contribute to the development of this type of scenario.

Summarizing the literature, a number of points are made clear. First, the media truism known as the YearTwo Effect remains locked in a hypothetical state. To date, there have been no studies conducted to explicitly examine this phenomenon, whether it exists in the contexts of the necessary control variables, and what its potential causes may be. Second, if the YearTwo Effect is an observable phenomenon, there are certain factors (e.g., recruiting rankings and regression to the mean) that need to be accounted for as likely predictors of improvement. Third, definitions of improvement and success are wide-ranging and may be dependent on the financial or historical status of the program being examined; as such, it would be wise to employ methods (e.g., school-level fixed effects, conference change variables, and strength of schedule metrics) that consider these potential differences.

\section{Methodology}

\subsection{Data}

The rvest package in $\mathrm{R}$ statistical software version 3.4.1 was used to scrape 11 seasons of FBS data from www.sports-reference.com/cfb and $w w w .247$ sports.com, two reliable online databases for historical college football statistics and recruiting rankings, respectively. The data were then organized into a balanced panel containing 11 seasons (2007-2017) of statistical, recruiting, and coaching observations from 114 Power Five and Group of Five programs $(\mathrm{N}=1,254 ; n=114, T=11){ }^{2}$

\subsection{Variables}

Each observation in the panel represented a single season and contained information on variables that were relevant to the examination. Table 1 lists and defines all of the variables that were used in the 
Table 1

List and descriptions of the variables

\begin{tabular}{|c|c|}
\hline Variable & Description \\
\hline COACHTENURE & $\begin{array}{l}\text { A vector of categorical dummy variables indicating whether the head coach during the observed } \\
\text { season was in his first }(Y 1) \text {, second }(Y 2) \text {, third }(Y 3) \text {, fourth }(Y 4) \text {, or fifth }(Y 5) \text { year with the } \\
\text { observed program; seasons in which the coach was in his sixth year or higher served as the } \\
\text { reference group. }\end{array}$ \\
\hline SOS & $\begin{array}{l}\text { A continuous strength of schedule measure showing how many points above or below average } \\
\text { (where } 0.0 \text { is average) a team's opponents were during the observed season. }\end{array}$ \\
\hline NEWCONF & $\begin{array}{l}\text { A categorical dummy variable that took on a value of } 1 \text { if the team was playing in a new } \\
\text { conference during the observed season and a value of } 0 \text { if otherwise. }\end{array}$ \\
\hline FRRk, SORk, JRRk, SRRk & $\begin{array}{l}\text { The national recruiting rankings for a team's freshman (FRRk), sophomore (SORk), junior } \\
(J R R k) \text {, and senior (SRRk) classes, as taken from } 247 \text { sports.com's composite rankings. }\end{array}$ \\
\hline REP_FIRED_PERF & $\begin{array}{l}\text { A series of categorical dummy variables that took on a value of } 1 \text { depending on the tenure of the } \\
\text { head coach during the observed season }(Y 1, Y 2, Y 3, Y 4 \text {, or } Y 5) \text { and if he had been hired to } \\
\text { replace a coach that was fired/forced to resign for on-field performance reasons. }\end{array}$ \\
\hline REP_FIRED_NONPERF & $\begin{array}{l}\text { Same as above except it only applied to observations in which head coaches had replaced coaches } \\
\text { who were fired for non-performance reasons (e.g., rule violations or legal issues). }\end{array}$ \\
\hline REP_NEWJOB & $\begin{array}{l}\text { Same as above except it only applied to observations where head coaches replaced coaches who } \\
\text { had voluntarily left their positions to take a new job. }\end{array}$ \\
\hline REP_RETIRED & $\begin{array}{l}\text { Same as above except it only applied to observations where a head coach had replaced a coach } \\
\text { that had voluntarily retired. }\end{array}$ \\
\hline REG_MEAN & $\begin{array}{l}\text { A regression to the mean variable denoting how much higher or lower a team's win percentage in } \\
\text { the prior season had been compared to its prior 3-year average for overall win percentage } \\
\left(W I N \%_{t-1}-\left(\left(W I N \%_{t-2}+W I N \%_{t-3}+W I N \%_{t-4}\right) / 3\right)\right) \text {. }\end{array}$ \\
\hline WIN\% & A team's overall winning percentage during the observed season. \\
\hline SRS & $\begin{array}{l}\text { Simple Rating System; a measure devised by sports-reference.com that rates a team on a } \\
\text { continuous scale based on how many points better or worse it was than an average team (where } \\
0.0 \text { is average), factoring in its margins of victory and the strength of its opponents. }\end{array}$ \\
\hline PENYDSPG & $\begin{array}{l}\text { Penalty yards per game; a statistic showing the average number of penalty yards, per game, } \\
\text { accrued by the observed team during the observed season. }\end{array}$ \\
\hline OTOVPG & $\begin{array}{l}\text { Offensive turnovers per game; a statistic showing the average number of offensive turnovers } \\
\text { committed by the observed team, per game, during the observed season. }\end{array}$ \\
\hline
\end{tabular}

analyses. There were two primary outcome variables of interest in this study: (1) a team's overall winning percentage (WIN\%) and (2) its Simple Rating System $(S R S)$ rating. Winning percentage, as the traditional and rather obvious measure of team performance, was calculated according to a team's overall record rather than its regular season or conference records. This was done to incorporate performance in relevant postseason games and to avoid the issues of variability that arise when conference winning percentages containing just a very small sample of games are analyzed. On the other hand, SRS is a rating system devised by sports-reference.com that takes into account average point differential and strength of schedule. For example, if a team won its games by an average of 5.1 points per game and played a schedule with opponents that were 1.5 points worse than average, it would have an SRS of 3.6. This rating would indicate the team was 3.6 points better than an average team, which would accordingly have an SRS value of $0.0 .^{3}$ Compared to winning percentage, it may serve as a more reliable indicator of team performance (Maxcy, 2013). Outcome variables representing seasonal changes in penalty yards per game (PENYDSPG) and offensive turnovers per game (OTOVPG) were also included in certain models.

In order to capture the essence of the Year-Two Effect, the outcome variables are frequently represented in the models as the associated increase or decrease from a prior season $(t-t-1)$. They are then regressed on a number of predictor variables, the most relevant of which are a series of categorical dummy variables indicating whether a school's head coach was in his first $(Y 1)$, second $(Y 2)$, third $(Y 3)$, fourth $(Y 4)$, or fifth $(Y 5)$ season with a program. Seasons in which a head coach was in his sixth season or higher served as the reference group. Other commonlyreferenced predictor variables included a strength of schedule (SOS) measure that quantified how many points above or below average a team's opponents were during a season; a conference change dummy variable $(N E W C O N F)$ that indicated whether a team was new to a conference during the observed season; and recruiting ranking variables (FRRk, SORk, $J R R k$, and $S R R k$ ) that were representative of a team's 247 sports.com national recruiting ranking for a given 
Table 2

Summary statistics for the variables

\begin{tabular}{|c|c|c|c|c|}
\hline Variable & Mean & Std. Dev. & Min. & Max. \\
\hline$\overline{W I N} \%_{t}-$ WIN\% $\%_{t-1}$ & 0.0006 & 0.2098 & -0.857 & 0.631 \\
\hline$S R S_{t}-S R S_{t-1}$ & 0.1128 & 7.0999 & -27.22 & 21.12 \\
\hline$S_{O S}-S_{t} O S_{t-1}$ & 0.0827 & 2.5092 & -7.08 & 9.07 \\
\hline$P E N Y D S P G_{t}-P E N Y D S P G_{t-1}$ & 0.8037 & 18.281 & -84.1 & 62.6 \\
\hline OTOVPG $_{t}-$ OTOVPG $_{t-1}$ & -0.0295 & 0.6249 & 6.5 & -7.6 \\
\hline$N E W C O N F_{t}$ & 0.0327 & 0.1778 & 0 & 1 \\
\hline$F R R k_{t}-F R R k_{t-1}$ & 0.1372 & 15.769 & -77 & 60 \\
\hline$S O R k_{t}-S O R k_{t-1}$ & 0.1603 & 16.138 & -77 & 60 \\
\hline$J R R k_{t}-J R R k_{t-1}$ & 0.1093 & 16.673 & -108 & 60 \\
\hline$S R R k_{t}-S R R k_{t-1}$ & 0.1667 & 17.283 & -108 & 74 \\
\hline COACHTENURE & 4.7791 & 4.7678 & 1 & 46 \\
\hline$R E G_{-} M E A N_{t}$ & 0.0032 & 0.1989 & -0.7763 & 0.6257 \\
\hline
\end{tabular}

class. Like the outcome variables, the predictor variables were frequently recorded as the change from the previous season. In this way, it could be seen whether increases or decreases in a certain variable were leading to increases or decreases in performance. Table 2 displays the summary statistics for the majority of these variables.

\subsection{Empirical specifications}

The plm package in $\mathrm{R}$ statistical software version 3.5.3 was used to conduct a series of twoway fixed effect panel regression analyses on the dataset $(\mathrm{N}=1,254 ; n=114, T=11)$. The two-way fixed effects model implies that unobserved heterogeneities in both the time periods (e.g., the seasons) and the programs were controlled for. The fixed effects were included given the frequency at which rules, conference affiliations, and postseason formats changed in the NCAA during the observed time period, and because each program operates within its own unique constraints; that is, even within the FBS there are less-tangible factors such as the history and reputation of a school that may vary widely between programs and influence on-field or recruiting performance. The school-specific fixed effects therefore control for the time-invariant differences between the schools so that the estimated coefficients of the fixed-effects models were not biased due to omitted time-invariant characteristics; in a similar manner, the seasonal fixed effects controlled for omitted time-variant characteristics that were consistent across schools (Torres-Reyna, 2010).

While the models addressing each specific research question contained differing sets of predictor and outcome variables, they all followed the same basic format:

$$
\begin{aligned}
& y_{i t}=X_{i t}^{\prime} \beta+e_{i}+h_{t}+u_{i t} \\
& (t \in\{1, \ldots, T\} ; i \in\{1, \ldots, N\}),
\end{aligned}
$$

where $y_{i t}$ is the outcome variable for school $i$ during season $t, X_{i t}^{\prime}$ is a $K \times 1$ vector of predictor variables, $\beta$ is the coefficient to be estimated for each predictor variable, $e_{i}$ is the fixed effect for each individual school, and $h_{t}$ is the time fixed effect for each season. Because $e_{i}$ is time invariant and considered part of the intercept, it is allowed to be correlated with other predictor variables. Fixed effects were estimated using the within effect estimation method:

$$
\left(y_{i t}-\bar{y}_{i}\right)=\left(x_{i t}-\bar{x}_{i .}\right)^{\prime} \beta+\left(\varepsilon_{i t}-\bar{\varepsilon}_{i .}\right),
$$

where $\bar{y}_{i}$ is the mean of the outcome variable for school $i$, the $\bar{x}_{i}$. represent the means of the predictor variables for school $i$, and $\bar{\varepsilon}_{i}$ is the mean error of school $i$. The same approach is taken for the seasonal fixed effects. Although its procedures are slightly different, the within effect estimation method produces $\beta$ coefficients that are identical to those that are produced when a least squares dummy variable (LSDV) approach is used to model the fixed effects (Park, 2011; Torres-Reyna, 2010). Each regression result table reports the average, school-specific fixed effect for that model.

\section{Results \& discussion}

\subsection{Is the year-two effect a significant phenomenon?}

The first step in this study involved analyzing whether or not the Year-Two Effect is a significant, observable phenomenon, or simply an availability heuristic that has become entrenched in the popu- 
Table 3

Top 12 season-to-season changes in WIN\% (Top) and SRS (Bottom) from 2007-2017

\begin{tabular}{llccc}
\hline School & Coach & Season & Change & Tenure \\
\hline Fresno State & Jeff Tedford (10-4) & 2017 & 0.631 & 1 \\
Miami (OH) & Michael Haywood (9-4) & 2010 & 0.631 & 2 \\
Auburn & Gus Malzahn (12-2) & 2013 & 0.607 & 1 \\
Air Force & Troy Calhoun (10-3) & 2014 & 0.602 & 8 \\
Texas Christian & Gary Patterson (12-1) & 2014 & 0.590 & 14 \\
UCF & Scott Frost (13-0) & 2017 & 0.538 & 2 \\
Ohio State & Urban Meyer (12-0) & 2012 & 0.538 & 1 \\
Western Michigan & P.J. Fleck (8-5) & 2014 & 0.532 & 2 \\
SMU & June Jones (8-5) & 2009 & 0.532 & 2 \\
Illinois & Ron Zook (9-4) & 2007 & 0.525 & 3 \\
Maryland & Ralph Friedgen (9-4) & 2010 & 0.525 & 10 \\
Rice & David Bailiff (10-3) & 2008 & 0.519 & 2 \\
\hline Louisiana Tech & Skip Holtz (9-5) & 2014 & 21.12 & 2 \\
Auburn & Gus Malzahn (12-2) & 2013 & 19.72 & 1 \\
UCF & Scott Frost (6-7) & 2016 & 18.84 & 1 \\
Georgia & Kirby Smart (13-2) & 2017 & 18.83 & 2 \\
Fresno State & Jeff Tedford (10-4) & 2017 & 18.73 & 1 \\
Purdue & Jeff Brohm (7-6) & 2017 & 18.70 & 1 \\
Rice & David Bailiff (10-3) & 2008 & 18.51 & 2 \\
Wyoming & Craig Bohl (8-6) & 2016 & 18.40 & 3 \\
Western Michigan & P.J. Fleck (8-5) & 2014 & 17.37 & 2 \\
Air Force & Troy Calhoun (10-3) & 2014 & 17.08 & 8 \\
Texas Christian & Gary Patterson (12-1) & 2014 & 17.02 & 14 \\
UCF & Scott Frost (13-0) & 2017 & 16.91 & 2 \\
\hline & & & &
\end{tabular}

lar press's stable of over-generalizations and clichés. On the surface, one could certainly be excused for believing this phenomenon. In addition to the list of well-known coaches who were highlighted in the introduction as beneficiaries of second-season success, Table 3 reveals that there is a higher proportion of second-year coaches among the top 12 coaches who have experienced the largest jumps in year-toyear performance from 2007 to 2017.

However, in order to address the overarching question, a more statistically-oriented approach is needed. As such, the study was first directed toward a series of analyses that compared the mean changes in WIN\% and SRS across different coaching tenures. Table 4 displays the results. As seen, a team's overall winning percentage will, on average, drop almost $2 \%$ during a coach's first season in charge. In year two, however, it improves by nearly $6 \%$, giving preliminary evidence of the Year-Two Effect. Moderate improvements are then typically witnessed in years three and four before the ceiling is reached and improvement declines, on average, in the fifth season and beyond. The significance levels reported in the third column represent $t$-tests between the mean change for year two and the mean changes of the other seasons. The resulting $p$-values indicate that the mean change in
Table 4

Mean changes in WIN\% and SRS from prior season by coach tenure

\begin{tabular}{lccc}
\hline Coach Tenure & Mean Change & Significance & $n$ \\
Year 1 & $-1.84 \%$ & $p<0.001$ & 236 \\
Year 2 & $5.76 \%$ & - & 211 \\
Year 3 & $1.48 \%$ & $p=0.018$ & 192 \\
Year 4 & $2.13 \%$ & $p=0.039$ & 156 \\
Year 5 & $-4.16 \%$ & $p<0.001$ & 105 \\
Years 6+ & $-2.48 \%$ & $p<0.001$ & 354 \\
\hline Year 1 & -0.532 & $p<0.001$ & 236 \\
Year 2 & 2.026 & - & 211 \\
Year 3 & 0.650 & $p=0.023$ & 192 \\
Year 4 & 0.560 & $p=0.017$ & 156 \\
Year 5 & -1.214 & $p<0.001$ & 105 \\
Years 6+ & -0.693 & $p<0.001$ & 354 \\
\hline
\end{tabular}

winning percentage during a coach's second season tends to be significantly different from those witnessed in the other seasons $(p<0.05)$. The results of the mean SRS comparisons show just as stark of a contrast, as second-year coaches tended to improve their teams by an average of 2.026 rating points. This mean value was significantly different from all other seasonal changes $(p<0.05)$, further highlighting the gains that are typically experienced in a coach's second year.

Nonetheless, while these initial $t$-tests provide evidence of the Year-Two Effect, a simple comparison of the averages is not enough. After all, there are additional variables that can influence season-to-season changes in performance that need to be controlled for in more advanced models. Equation 3 identifies the first two-way fixed effects model that was used:

$$
\begin{aligned}
y_{i t}-y_{i t-1}= & \beta_{1} \text { COACHTENURE }_{i t}+\beta_{2}\left(\operatorname{SOS}_{i t}\right. \\
& \left.-\operatorname{SOS}_{i t-1}\right)+\beta_{3} N E W C O N F_{i t} \\
& +\beta_{4}\left(J R R k_{i t}-J R R k_{i t-1}\right)+\beta_{5}\left(\operatorname{SRRk}_{i t}\right. \\
& -S_{\left.R R k_{i t-1}\right)+e_{i}+h_{t}+u_{i t},}
\end{aligned}
$$

where $y_{i t}-y_{i t-1}$ is the outcome variable representing the change in WIN\% or SRS from the previous season for team $i$ during season $t, C O A C H T E N U R E$ is the vector of dummy variables indicating the current head coach's tenure $(Y 1, Y 2, Y 3, Y 4$, or $Y 5)$, SOS captures the increase or decrease in the difficulty of a team's schedule from the prior season, $N E W C O N F$ indicates whether or not a team was in a new conference during the observed season, JRRk and SRRk show how much better or worse a team's junior and senior classes were in terms of national recruiting rankings from the season before, and the $e_{i}$ and $h_{t}$ are the fixed effects for school and season, respectively.

The basic intent of this model was to control for factors outside of a second-year head coach's influ- 
Table 5

Two-way fixed effects panel regression results: Equation 3

\begin{tabular}{|c|c|c|c|c|}
\hline Variable & $\beta$ & S.E. & t-value & $p$-value \\
\hline \multicolumn{5}{|l|}{$y=W I N \%_{t}-W I N \%_{t-1}$} \\
\hline $\mathrm{Y} 1_{\mathrm{t}}$ & 0.0313 & 0.0205 & 1.5266 & 0.1271 \\
\hline $\mathrm{Y} 2_{\mathrm{t}}$ & 0.1042 & 0.0217 & 4.9230 & $0.0000^{* * *}$ \\
\hline $\mathrm{Y} 3_{\mathrm{t}}$ & 0.0632 & 0.0218 & 2.9057 & $0.0037^{* * *}$ \\
\hline $\mathrm{Y}_{\mathrm{t}}$ & 0.0509 & 0.0231 & 2.1998 & $0.0280^{* *}$ \\
\hline $\mathrm{Y}_{\mathrm{t}}$ & -0.0117 & 0.0258 & -0.4525 & 0.6510 \\
\hline $\mathrm{SOS}_{\mathrm{t}}-\mathrm{SOS}_{\mathrm{t}-1}$ & -0.0134 & 0.0024 & -5.4822 & $0.0000^{* * *}$ \\
\hline $\mathrm{NEWCONF}_{\mathrm{t}}$ & -0.0454 & 0.0374 & -1.2160 & 0.2243 \\
\hline $\mathrm{JRRk}_{\mathrm{t}}-\mathrm{JRRk}_{\mathrm{t}-1}$ & -0.0008 & 0.0004 & -1.9639 & $0.0410^{* *}$ \\
\hline $\mathrm{SRRk}_{\mathrm{t}}-\mathrm{SRRk}_{\mathrm{t}-1}$ & -0.0008 & 0.0004 & -1.9149 & $0.0558^{*}$ \\
\hline Avg. School Fixed Effect & -0.035 & & & \\
\hline Within $\mathrm{R}^{2}$ & 0.058 & & & \\
\hline F-Test & $7.708^{* * *}$ & & & \\
\hline \multicolumn{5}{|l|}{$y=\mathrm{SRS}_{\mathrm{t}}-\mathrm{SRS}_{\mathrm{t}-1}$} \\
\hline $\mathrm{Y} 1_{\mathrm{t}}$ & 0.9347 & 0.6926 & 1.3496 & 0.1774 \\
\hline $\mathrm{Y} 2_{\mathrm{t}}$ & 3.5429 & 0.7144 & 4.9590 & $0.0000^{* * *}$ \\
\hline $\mathrm{Y} 3_{\mathrm{t}}$ & 2.2523 & 0.7343 & 3.0675 & $0.0022^{* * *}$ \\
\hline $\mathrm{Y}_{\mathrm{t}}$ & 1.8298 & 0.7804 & 2.3448 & $0.0192^{* *}$ \\
\hline $\mathrm{Y}_{\mathrm{t}}$ & -0.5520 & 0.8725 & -0.6327 & 0.5271 \\
\hline $\mathrm{SOS}_{\mathrm{t}}-\mathrm{SOS}_{\mathrm{t}-1}$ & 0.4196 & 0.0823 & 5.0967 & $0.0000^{* * *}$ \\
\hline $\mathrm{NEWCONF}_{\mathrm{t}}$ & -2.0528 & 1.2613 & -1.6275 & 0.1039 \\
\hline $\mathrm{JRRk}_{\mathrm{t}}-\mathrm{JRRk}_{\mathrm{t}-1}$ & -0.0394 & 0.0146 & -2.7013 & $0.0070^{* * *}$ \\
\hline $\mathrm{SRRk}_{\mathrm{t}}-\mathrm{SRRk}_{\mathrm{t}-1}$ & -0.0389 & 0.0139 & -2.7987 & $0.0052^{* * *}$ \\
\hline Avg. School Fixed Effect & -1.142 & & & \\
\hline Within $\mathrm{R}^{2}$ & 0.059 & & & \\
\hline F-Test & $7.805^{* * *}$ & & & \\
\hline
\end{tabular}

${ }^{*} p<0.10 ;{ }^{* *} p<0.05 ;{ }^{* * *} p<0.01$.

ence that might be affecting overall performance. By including the changes in a team's national recruiting rank from the prior season for the current junior and senior classes, the coming of age of the talent brought in by a former coach was suitably controlled for in observations where coaches were in their second years. ${ }^{4}$ Similarly, changes in schedule difficulty and conference affiliation needed to be controlled for since they, too, are factors external to the head coach that could lead to increases or decreases in performance. Table 5 reports the results of the WIN\% and SRS models.

As seen in the $Y 2$ coefficient, the Year-Two Effect is highly significant, even in the face of schedule changes, conference changes, and the development of the talent brought in by the former coaching staff. Controlling for the fixed effects and holding all other variables constant, a program can expect to improve on its winning percentage from the prior season by approximately 10\% during the head coach's second season. A similar effect is seen in the SRS model, where a second-year coach will generally see his team improve by 3.5 points in the ratings. In both models, programs also appear to improve significantly-compared to the reference group-during coaches' third and fourth seasons, though the effect sizes of these variables are roughly half the size of the improvements that are seen moving from year one to year two. Year-one and year-five changes were non-significant in the models.

In regards to the other explanatory variables serving as the controls, strength of schedule (SOS) was unsurprisingly significant in both models, indicating that more difficult schedules lead to lower winning percentages and higher SRS ratings (which is to be expected given that SOS is one of the main components of SRS). Season-to-season changes in the JRRk and $S R R k$ variables also had significant effects on performance, in both cases indicating that junior and senior classes with higher (worse) ratings compared to the prior season's classes led to marginal declines in $W I N \%$ and SRS. Conference changes did not appear to have a significant impact on year-to-year changes in either outcome variable.

Putting all of this information together, the YearTwo Effect appears to be a significant phenomenon that is consistent across all 114 FBS programs, their conferences, and the 11 seasons that were examined; however, there also appear to be significant improvements made in the third and fourth seasons. Though these effects are not as pronounced as the improvement that is generally made between a head coach's first and second season, they nonetheless show that some coaches may begin righting the ship in their third and fourth seasons. While the second season may typically play witness to the biggest jumps in performance, the third and fourth seasons also present opportunities for improvement. Interestingly, improvement seems to dissipate between the fourth and fifth seasons. One can also expect team performance during a head coach's first season to be similar to team performance during the old coach's final season.

\subsection{What factors contribute to the year-two effect?}

Seeing as the Year-Two Effect appears to be a statistically supported phenomenon, the next step in the process involved examining those factors that could theoretically and practically be contributing to its existence. In addition to enhancing the general understanding of this phenomenon, further explo- 
ration of this issue holds strong practical implications for administrators who may be looking for underlying traits in prospective coaches, and for coaches who may want to place an added emphasis on factors that contribute to a quick turnaround.

As previously identified in the review of literature, recruiting talent is frequently positioned as a variable that can influence team performance (Herda et al., 2009; Caro, 2012; Maxcy, 2013). This is also a variable that aligns with one of a coaching staff's key responsibilities of bringing new talent into a program to replace current or former players. The two-way fixed effects panel regression model used to examine how changes in recruiting performance are impacted by coaching tenure is presented in Equation 4:

$$
\begin{aligned}
& y_{i t}-y_{i t-1}=\beta_{1} \text { COACHTENURE } E_{i t}+\beta_{2} N E W C O N F_{i t} \\
& +\beta_{3}\left(W I N \%_{i t-1}-W I N \%_{i t-2}\right)+h_{t}+u_{i t},
\end{aligned}
$$

where $y_{i t}-y_{i t-1}$ is the change in team $i$ 's national recruiting ranking (FRRk) from the previous season, WIN $\%_{i t-1}-$ WIN $_{i t-2}$ captures changes in team performance prior to the signing of the observed recruiting class, and all other parameters are as previously defined. Given that prior studies have shown that on-field success can lead to better recruiting (Herda et al., 2009; Maxcy, 2013), the inclusion of the variable that captured changes in team performance in the season prior to the signing of the recruiting class was viewed as being necessary. In addition, suggestions are frequently made that moving to a new conference can open new recruiting pipelines (Bird, 2017), so the $N E W C O N F$ variable was also included for the impact it might have on year-to-year changes in recruiting rankings. The coaching tenure variables, as the parameters of interest, were also retained in the model. Table 6 displays the results.

These results again depict a relatively clear secondyear effect, this time in terms of changes in a program's national recruiting rankings. During a coach's second season, the team's national recruiting rankings were expected to improve by approximately eight to nine spots from the prior season, holding all other variables constant. ${ }^{5}$ In line with what was seen in prior literature (Maxcy, 2013), a new coach's first season with a program will actually see a team fall in the national recruiting rankings by three to four spots. Therefore, it certainly appears as though one of the potential drivers of the Year-Two Effect is better recruiting, as recently hired coaches are generally able to bring in higher quality players once
Table 6

Two-way fixed effects panel regression results: Equation 4

\begin{tabular}{lcccc}
\hline Variable & $\beta$ & S.E. & t-value & $p$-value \\
$y=$ FRRk $_{\mathrm{t}}-$ FRRk $_{\mathrm{t}-1}$ & & & & \\
$\mathrm{Y}_{\mathrm{t}}$ & 3.701 & 1.534 & 2.595 & $0.016^{* *}$ \\
$\mathrm{Y}_{\mathrm{t}}$ & -8.516 & 1.579 & -5.316 & $0.000^{* * *}$ \\
$\mathrm{Y}_{\mathrm{t}}$ & 0.294 & 1.624 & 0.192 & 0.856 \\
$\mathrm{Y}_{\mathrm{t}}$ & 3.244 & 1.706 & 2.018 & $0.057^{*}$ \\
$\mathrm{Y}_{\mathrm{t}}$ & 3.579 & 1.914 & 1.776 & $0.061^{*}$ \\
$\mathrm{NEWCONF}_{\mathrm{t}}$ & -2.380 & 2.790 & -0.997 & 0.319 \\
WIN\% $\mathrm{t}_{\mathrm{t}}-\mathrm{WIN \%}_{\mathrm{t}-2}$ & -3.912 & 2.206 & -1.737 & $0.076^{*}$ \\
\hline Avg. School Fixed Effect & 0.208 & & & \\
Within R2 & 0.072 & & & \\
F-Test & $12.347^{* * *}$ & & & \\
${ }^{*} p<0.10 ;{ }^{* *} p<0.05 ;{ }^{* * *} p<0.01$. & & & \\
\end{tabular}

some certainty and stability have been added to the program. The year-four and year-five coefficients, to a more marginal extent, also displayed significant effects, though both were indicative of declines in a coach's recruiting prowess compared to the prior season.

Better talent, however, is not the only reason why the Year-Two Effect is frequently perceived as being a consistent phenomenon. Media members, after all, frequently attribute greater discipline and chemistry being instilled in the team as a key driver of the Year-Two Effect (Hokanson, 2008; Emerson, 2017). Fortunately, the sport of football provides a couple of statistics-penalties and turnovers-which can be used as proxies for discipline and chemistry. Variations of these two statistics were therefore included as the outcome variables in the following set of models:

$$
\begin{aligned}
& y_{i t}-y_{i t-1} \\
& =\beta_{1} \text { COACHTENURE }_{i t}+\beta_{2}\left(\operatorname{SOS}_{i t-1}\right) \\
& \quad+\beta_{3}\left(\text { FRR }_{i t}-\text { FRRk }_{i t-1}\right) \\
& \quad+\beta_{4}\left(\operatorname{SORk}_{i t}-\operatorname{SOR}_{i t-1}\right)+\beta_{5}\left(J R R k_{i t}-J R R k_{i t-1}\right) \\
& \quad+\beta_{6}\left(\operatorname{SRRk}_{i t}-S R R k_{i t-1}\right)+e_{i}+h_{t}+u_{i t},
\end{aligned}
$$

where $y_{i t}-y_{i t-1}$ is the increase or decrease in penalty yards (PENYDSPG), or offensive turnovers per game (OTOVPG) from the prior season committed by team $i$ during season $t$, the seasonal increase or decrease in $S O S$ is included as an explanatory variable since more difficult competition might cause a team to commit more penalties or turnovers, and the changes in each recruiting class's talent level (FRRk, $S O R k$, JRRk, and $S R R k$ ) from the prior season were included to account for talent fluctuation and the possibility that player development and an influx of more or less talented players via graduation or recruitment 
Table 7

Two-way fixed effects panel regression results: Equation 5

\begin{tabular}{|c|c|c|c|c|}
\hline Variable & $\beta$ & S.E. & t-value & $p$-value \\
\hline \multicolumn{5}{|c|}{$y=P E N Y D S P G_{t}-P E N Y D S P G_{t-1}$} \\
\hline $\mathrm{Y} 1_{\mathrm{t}}$ & 0.761 & 1.757 & 0.433 & 0.6652 \\
\hline $\mathrm{Y} 2_{\mathrm{t}}$ & -1.809 & 1.830 & -0.989 & 0.3230 \\
\hline $\mathrm{Y} 3_{\mathrm{t}}$ & -0.869 & 1.887 & -0.461 & 0.6452 \\
\hline $\mathrm{Y} 4_{\mathrm{t}}$ & -0.972 & 1.983 & -0.490 & 0.6240 \\
\hline $\mathrm{Y}_{\mathrm{t}}$ & 0.811 & 2.208 & 0.368 & 0.7132 \\
\hline $\mathrm{SOS}_{\mathrm{t}}-\mathrm{SOS}_{\mathrm{t}-1}$ & -0.198 & 0.208 & -0.949 & 0.3428 \\
\hline $\mathrm{FRRk}_{\mathrm{t}}-\mathrm{FRRk}_{\mathrm{t}-1}$ & 0.051 & 0.042 & 1.216 & 0.2242 \\
\hline $\mathrm{SORk}_{\mathrm{t}}-\mathrm{SORk}_{\mathrm{t}-1}$ & -0.010 & 0.048 & -0.202 & 0.8399 \\
\hline $\mathrm{JRRk}_{\mathrm{t}}-\mathrm{JRRk}_{\mathrm{t}-1}$ & 0.002 & 0.047 & 0.053 & 0.9574 \\
\hline $\mathrm{SRRk}_{\mathrm{t}}-\mathrm{SRRk}_{\mathrm{t}-1}$ & 0.019 & 0.038 & 0.494 & 0.6212 \\
\hline Avg. School Fixed Effect & 1.159 & & & \\
\hline Within R2 & 0.007 & & & \\
\hline F-Test & 0.795 & & & \\
\hline \multicolumn{5}{|c|}{$y=\mathrm{OTOVPG}_{\mathrm{t}}-\mathrm{OTOVPG}_{\mathrm{t}-1}$} \\
\hline $\mathrm{Y} 1_{\mathrm{t}}$ & -0.030 & 0.063 & -0.477 & 0.6334 \\
\hline $\mathrm{Y} 2_{\mathrm{t}}$ & -0.229 & 0.065 & -3.509 & $0.0005^{* * *}$ \\
\hline $\mathrm{Y} 3_{\mathrm{t}}$ & -0.091 & 0.067 & -1.351 & 0.1769 \\
\hline $\mathrm{Y}_{\mathrm{t}}$ & -0.127 & 0.071 & -1.792 & $0.0734^{*}$ \\
\hline $\mathrm{Y} 5_{\mathrm{t}}$ & -0.035 & 0.079 & -0.446 & 0.6559 \\
\hline $\mathrm{SOS}_{t}-\mathrm{SOS}_{\mathrm{t}-1}$ & 0.005 & 0.007 & 0.692 & 0.4887 \\
\hline $\mathrm{FRRk}_{\mathrm{t}}-\mathrm{FRRk}_{\mathrm{t}-1}$ & 0.001 & 0.001 & 0.373 & 0.7091 \\
\hline $\mathrm{SORk}_{\mathrm{t}}-\mathrm{SORk}_{\mathrm{t}-1}$ & -0.001 & 0.002 & -0.676 & 0.4990 \\
\hline $\mathrm{JRRk}_{\mathrm{t}}-\mathrm{JRRk}_{\mathrm{t}-1}$ & 0.000 & 0.002 & 0.151 & 0.8801 \\
\hline $\mathrm{SRRk}_{\mathrm{t}}-\mathrm{SRRk}_{\mathrm{t}-1}$ & 0.002 & 0.001 & 1.274 & 0.2028 \\
\hline Avg. School Fixed Effect & & 0.047 & & \\
\hline Within R2 & & 0.019 & & \\
\hline F-Test & & $2.112^{* *}$ & & \\
\hline
\end{tabular}

${ }^{*} p<0.10 ;{ }^{* *} p<0.05 ;{ }^{* * *} p<0.01$.

might lead to variations in the number of penalties or turnovers being committed. These models controlled for talent across all four recruiting classes in order to see whether the chemistry, discipline, and/or schemes instilled by a head coach of a certain tenure were influential outside of the playing talent moving in and out of the program. Table 7 displays the results of these two models.

Looking first at $P E N Y D S P G_{t}-P E N Y D S P G_{t-1}$ regressed on the included predictor variables, it becomes clear that none of the variables were significant predictors of a team's penalties. Indeed, penalties seem to be rather random from year-to-year, and the variables indicating the tenure of the observed coach do not appear to impart any kind of signifi- cant influence on a team's tendency to get flagged. The Year-Two Effect, it seems, is not driven by second-year coaches instilling more discipline and getting their teams to commit fewer costly penalties. Turnovers per game, however, did display a significantly positive turnaround in coaches' second seasons. The resulting effect size suggests that teams with second-year head coaches will commit nearly 0.23 fewer offensive turnovers per game than they did the prior season, a value that averages out to nearly three fewer turnovers over the length of an entire regular season.

This trend could be the result of a few different drivers. As was previously shown, programs with second-year coaches tend to recruit better players, which implies that more talented quarterbacks and running backs could be coming into the squad and committing fewer turnovers than their predecessors committed. Nevertheless, with the model controlling for this possibility through the inclusion of the recruiting variables, it is possible the additional decline in turnovers is attributable to a second-year coach having had adequate time get the proper pieces in place and to install their specific scheme or system. As the proper players become immersed in this system, and ball security is continually emphasized, offensive turnovers would be expected to decline. It is therefore suggested that future studies in this field examine the impact that specific scheme changes can have on performance.

Continuing, it is important to look at the specific situation that each coach entered into upon being hired. This is a particularly important step to take before making practical recommendations because the status of a program upon arrival will influence how much room there is for improvement or decline. More specifically, one would expect a positive regression toward the mean in subsequent seasons if a coach was taking over a historically successful program that was coming off one of its worst seasons in school history (i.e., there is nowhere to go but up). Similarly, if a coach is coming in to replace a coach that left for a new job following a highly successful season, one would expect the team's performance level to decline or-in the best case scenario-simply remain steady in the seasons that followed (i.e., nowhere to go but down). Regression to the mean, after all, has been positioned as a potential influencer of second-season success (Connelly, 2016).

Therefore, in order to analyze whether the YearTwo Effect is a phenomenon that differs according to the status of a program when a coach takes over, 
the coaching tenure variables were recoded to represent the specific scenarios that a coach could be entering into; that is, new sets of categorical dummy variables were created to represent if a coach had begun his tenure following (1) the firing or resignation of the prior head coach for on-field, performancebased reasons (REP_FIRED_PERF), (2) the firing or resignation of the prior coach for non-performance reasons, such as a public relations scandal or NCAA/legal violation (REP_FIRED_NONPERF), (3) the departure of the former coach for a new job (REP_NEWJOB), or (4) the retirement of the prior coach under his own terms (REP_RETIRED). ${ }^{6}$ These variables were then inserted in place of the basic tenure variables that had been used in Equation 3's model. Tables 8 and 9 display the results for the WIN\% and SRS models, respectively.

Interestingly, the second season does appear to remain a sweet spot of sorts in nearly every scenario, even while controlling for changes in strength

Table 8

Two-way fixed effects panel regression results with revised tenure variables $($ WIN\%)

\begin{tabular}{|c|c|c|c|c|}
\hline Variable & $\beta$ & S.E. & t-value & $p$-value \\
\hline \multicolumn{5}{|l|}{$y=W I N \%_{t}-$ WIN $_{t-1}$} \\
\hline REP_FIRED_PERF (Y1) & 0.1063 & 0.0240 & 4.4247 & $0.0000^{\text {**** }}$ \\
\hline REP_FIRED_PERF (Y2) & 0.1342 & 0.0250 & 5.3618 & $0.0000^{* * *}$ \\
\hline REP_FIRED_PERF (Y3) & 0.0762 & 0.0258 & 2.9518 & $0.0032^{* * *}$ \\
\hline REP_FIRED_PERF (Y4) & 0.0680 & 0.0270 & 2.5187 & $0.0119^{* *}$ \\
\hline REP_FIRED_PERF (Y5) & -0.0255 & 0.0298 & -0.8554 & 0.3925 \\
\hline REP_FIRED_NONPERF (Y1) & -0.0785 & 0.0629 & -1.2484 & 0.2121 \\
\hline REP_FIRED_NONPERF (Y2) & -0.0122 & 0.0855 & -0.1420 & 0.8871 \\
\hline REP_FIRED_NONPERF (Y3) & -0.0133 & 0.0800 & -0.1664 & 0.8679 \\
\hline REP_FIRED_NONPERF (Y4) & -0.1114 & 0.1007 & -1.1053 & 0.2693 \\
\hline REP_FIRED_NONPERF (Y5) & 0.1181 & 0.1575 & 0.7500 & 0.4534 \\
\hline REP_NEWJOB (Y1) & -0.1307 & 0.0317 & -4.1231 & $0.0000^{* * *}$ \\
\hline REP_NEWJOB (Y2) & 0.0267 & 0.0327 & 0.8179 & 0.4136 \\
\hline REP_NEWJOB (Y3) & 0.0178 & 0.0340 & 0.5288 & 0.5971 \\
\hline REP_NEWJOB (Y4) & -0.0199 & 0.0383 & -0.5200 & 0.6032 \\
\hline REP_NEWJOB (Y5) & 0.0195 & 0.0462 & 0.4225 & 0.6727 \\
\hline REP_RETIRED (Y1) & 0.0514 & 0.0462 & 1.1116 & 0.2665 \\
\hline REP_RETIRED (Y2) & 0.1148 & 0.0481 & 2.3858 & $0.0172^{* *}$ \\
\hline REP_RETIRED (Y3) & 0.0864 & 0.0519 & 1.6646 & $0.0963^{*}$ \\
\hline REP_RETIRED (Y4) & 0.1422 & 0.0601 & 2.3666 & $0.0181^{* *}$ \\
\hline REP_RETIRED (Y5) & -0.0038 & 0.0788 & -0.0478 & 0.9619 \\
\hline $\mathrm{SOS}_{\mathrm{t}}-\mathrm{SOS}_{\mathrm{t}-1}$ & -0.0131 & 0.0024 & -5.4599 & $0.0000^{* * * *}$ \\
\hline $\mathrm{NEWCONF}_{\mathrm{t}}$ & -0.0420 & 0.0366 & -1.1461 & 0.2520 \\
\hline $\mathrm{JRRk}_{\mathrm{t}}-\mathrm{JRRk}_{\mathrm{t}-1}$ & -0.0010 & 0.0004 & -2.2650 & $0.0237^{* *}$ \\
\hline $\mathrm{SRRk}_{\mathrm{t}}-\mathrm{SRRk}_{\mathrm{t}-1}$ & -0.0008 & 0.0004 & -2.0304 & $0.0426^{* *}$ \\
\hline Avg. School Fixed Effect & -0.031 & & & \\
\hline Within $\mathrm{R}^{2}$ & 0.112 & & & \\
\hline F-Test & $5.826^{* * *}$ & & & \\
\hline
\end{tabular}

${ }^{*} p<0.10 ;{ }^{* *} p<0.05 ;{ }^{* * *} p<0.01$.
Table 9

Two-way fixed effects panel regression results with revised tenure variables $(S R S)$

\begin{tabular}{|c|c|c|c|c|}
\hline Variable & $\beta$ & S.E. & $\mathrm{t}$-value & $p$-value \\
\hline \multicolumn{5}{|l|}{$y=S R S_{t}-S R S_{t-1}$} \\
\hline REP_FIRED_PERF (Y1) & 3.3371 & 0.8111 & 4.1142 & $0.0000^{* * *}$ \\
\hline REP_FIRED_PERF (Y2) & 4.9328 & 0.8451 & 5.8370 & $0.0000^{* * * *}$ \\
\hline REP_FIRED_PERF (Y3) & 2.9415 & 0.8714 & 3.3755 & $0.0008^{* * *}$ \\
\hline REP_FIRED_PERF (Y4) & 2.1011 & 0.9115 & 2.3052 & $0.0213^{* *}$ \\
\hline REP_FIRED_PERF (Y5) & -0.6078 & 1.0067 & -0.6037 & 0.5462 \\
\hline REP_FIRED_NONPERF (Y1) & -2.6281 & 2.1225 & -1.2382 & 0.2159 \\
\hline REP_FIRED_NONPERF (Y2) & 0.7855 & 2.8881 & 0.2720 & 0.7857 \\
\hline REP_FIRED_NONPERF (Y3) & -0.7937 & 2.7010 & -0.2938 & 0.7689 \\
\hline REP_FIRED_NONPERF (Y4) & -1.7396 & 3.4013 & -0.5114 & 0.6091 \\
\hline REP_FIRED_NONPERF (Y5) & 1.8399 & 5.3169 & 0.3461 & 0.7294 \\
\hline REP_NEWJOB (Y1) & -4.7047 & 1.0702 & -4.3962 & $0.0000^{* * *}$ \\
\hline REP_NEWJOB (Y2) & 0.3254 & 1.1037 & 0.2949 & 0.7682 \\
\hline REP_NEWJOB (Y3) & 0.3678 & 1.1485 & 0.3203 & 0.7488 \\
\hline REP_NEWJOB (Y4) & 0.3667 & 1.2942 & 0.2833 & 0.7770 \\
\hline REP_NEWJOB (Y5) & -0.0240 & 1.5597 & -0.0154 & 0.9877 \\
\hline REP_RETIRED (Y1) & 2.6615 & 1.5607 & 1.7053 & $0.0884^{*}$ \\
\hline REP_RETIRED (Y2) & 3.2942 & 1.6249 & 2.0274 & $0.0429^{* *}$ \\
\hline REP_RETIRED (Y3) & 2.8930 & 1.7520 & 1.6513 & $0.0990^{*}$ \\
\hline REP_RETIRED (Y4) & 3.9462 & 2.0281 & 1.9457 & $0.0519^{*}$ \\
\hline REP_RETIRED (Y5) & -1.2201 & 2.6615 & -0.4584 & 0.6467 \\
\hline $\mathrm{SOS}_{\mathrm{t}}-\mathrm{SOS}_{\mathrm{t}-1}$ & 0.4328 & 0.0809 & 5.3521 & $0.0000^{* * *}$ \\
\hline $\mathrm{NEWCONF}_{\mathrm{t}}$ & -1.8888 & 1.2372 & -1.5266 & 0.1271 \\
\hline $\mathrm{JRRk}_{\mathrm{t}}-\mathrm{JRRk}_{\mathrm{t}-1}$ & -0.0449 & 0.0144 & -3.1093 & $0.0019^{* * *}$ \\
\hline $\mathrm{SRRk}_{\mathrm{t}}-\mathrm{SRRk}_{\mathrm{t}-1}$ & -0.0424 & 0.0137 & -3.0871 & $0.0021^{* * *}$ \\
\hline Avg. School Fixed Effect & -1.005 & & & \\
\hline Within $\mathrm{R}^{2}$ & 0.113 & & & \\
\hline F-Test & $5.848^{* * *}$ & & & \\
\hline
\end{tabular}

of schedule, conference, and the talent brought in by former coaches. Only in rare situations where coaches were fired for non-performance reasons do there not appear to be any significant differences in performance based on coaching tenure. Looking first at coaching tenure for coaches who had taken over following the firing of the previous coach for on-field performance reasons, it was seen that the first, second, third, and fourth seasons all tended to lead to highly significant improvements in both WIN\% and SRS. Nonetheless, the largest effects were seen in the second season, as the models indicated general improvements of $13.42 \%$ and 4.9 points in WIN\% and $S R S$, respectively. By contrast, improvements in the next closest tenure variable, season one, were $10.63 \%$ and 3.3 points. A second-season effect was also evident when the observed coach had replaced a retiring coach in both models, though it should be noted that a fourth season effect with a slightly larger effect size 
was also present. In terms of replacing coaches that had left to take new jobs, only the first season displayed a significant difference from the other seasons; however, it depicted a negative relationship whereby WIN\% and SRS tended to decline by $13.07 \%$ and 4.7 points, respectively, during a coach's first season at the helm. This negative effect appeared to wear off during the second season, though, as none of the remaining tenure variables were significant.

Overall, these results are rather intuitive. Coaches who were fired for performance-related reasons were likely coming off a season or series of seasons that were subpar; therefore, the new coach can be expected to turn things around rather quickly, as witnessed by the significant and positive effects in seasons one through four. Conversely, prior head coaches who had departed for a new job likely did so following a period of unprecedented success, meaning the new head coach had little room for improvement. Furthermore, the prior coach may have taken the bulk of his coaching staff and all of their systems and schemes to the new job, leaving the new coaching staff with players that might not fit their specific style. There might have also been a recruiting gap between the departure of the old coach and the arrival of the new one, causing the new coaching staff to struggle to immediately replicate the positive performances of the prior regime. Lastly, the significant year-two effect occurring after the replacement of a retired coach is also intriguing because it hints at the likelihood that it was time for these coaches to step down. Although they left on their own terms, they had likely been coasting on their past accomplishments. This steady state of mediocrity allows for a new leader to come in and take the team to the next level once he raises the intensity and gets his own players and schemes in place.

Finally, in order to more quantitatively capture the effects of regression to the mean, the authors revised their initial model to include an explanatory variable (REG_MEAN) representing how much higher or lower the prior season's win percentage had been compared to its prior 3-year average for win percentage $\left(W I N \%_{t-1}-\left(\left(W I N \%_{t-2}+W I N \%_{t-3}+W I N \%_{t-4}\right) /\right.\right.$ $3)$ ). In this way, any natural regression to the mean that occurred from a prior season being higher or lower than the program's previous average could be controlled for and tested for significance. Apart from the addition of this REG MEAN variable, the two-way fixed effects model and its associated variables were identical to those presented in Equation 3. Table 10 displays the results.
Table 10

Two-Way Fixed Effects Panel Regression Results with REG $M E A N$

\begin{tabular}{lcccc}
\hline Variable & $\beta$ & S.E. & t-value & $p$-value \\
\hline$y=W I N \%_{t}-W_{I N} \%_{t-1}$ & & & & \\
Y1 $_{\mathrm{t}}$ & 0.0092 & 0.0186 & 0.4938 & 0.6215 \\
$\mathrm{Y}_{\mathrm{t}}$ & 0.0790 & 0.0191 & 4.1276 & $0.0000^{* * *}$ \\
$\mathrm{Y}_{\mathrm{t}}$ & 0.0730 & 0.0196 & 3.7177 & $0.0002^{* * *}$ \\
$\mathrm{Y}_{\mathrm{t}}$ & 0.0766 & 0.0209 & 3.6637 & $0.0003^{* * *}$ \\
$\mathrm{Y}_{\mathrm{t}}$ & 0.0178 & 0.0234 & 0.7616 & 0.4465 \\
SOS $_{\mathrm{t}}-$ SOS $_{\mathrm{t}-1}$ & -0.0102 & 0.0022 & -4.6398 & $0.0000^{* * *}$ \\
NEWCONF $_{\mathrm{t}}$ & -0.0393 & 0.0337 & -1.1662 & 0.2438 \\
JRRk $_{\mathrm{t}}-\mathrm{JRRk}_{\mathrm{t}-1}$ & -0.0003 & 0.0004 & -0.7800 & 0.4356 \\
SRRk $_{\mathrm{t}}-$ SRRk $_{\mathrm{t}-1}$ & -0.0004 & 0.0004 & -1.1149 & 0.2651 \\
REG_MEAN $_{\text {Avg. School Fixed Effect }}-0.4590$ & 0.0285 & -16.0765 & $0.0000^{* * *}$ \\
Within R2 $^{\text {F-Test }}$ & 0.235 & & & \\
${ }^{*} p<0.10 ;{ }^{* *} p<0.05 ;{ }^{* * *} p<0.01$. & & & \\
\end{tabular}

Interestingly, the Year-Two Effect remains significant, albeit with an effect size $(\beta=0.079)$ that is just slightly larger than the significant effects also witnessed in years three $(\beta=0.073)$ and four $(\beta=0.077)$. The regression to the mean variable is highly significant and impactful, $\beta=-0.459, t(1120)=-16.077$, $p<.001$, indicating that for every $1 \%$ higher (lower) a team's WIN\% had been in the previous season compared to the average WIN\% of the prior three seasons, its WIN\% in the observed season would decline (improve) by nearly half a percent, holding all else constant. Including this variable certainly explains away a high degree of the additional effects that were witnessed in the initial model's $Y 2$ variable, further validating the assumption that regression to the mean plays a heavy role in determining the magnitude of the Year-Two Effect and other yearly effects. That being said, this final model reaffirms that, holding all else constant, a program's WIN\% will often start to significantly improve in a head coach's second season at the helm; furthermore, the improvements witnessed at this stage are larger than those across any of the other tenure variables. Although its impact is mitigated, the Year-Two Effect remains significant in comparison to most other years in a head coach's term.

\section{Conclusion}

\subsection{Summary of results}

In closing, the analyses conducted in this study helped shed more light on the commonly-held assumption that FBS football programs will take their 
largest leaps forward during a head coach's second season in charge. Known as the Year-Two Effect, this proposition has become a frequently-cited cliché among media members and other stakeholders in college football as they seek to predict or explain the improvements being made in a program. Analyzing 11 seasons of data for 114 FBS teams that played from 2007 to 2017, a series of $t$-tests revealed that secondseason changes in performance were significantly improved over the changes that occurred between the other seasons of head coaching tenure. Using twoway fixed effects regression models to account for the unobservable differences between schools and time periods, and including explanatory variables that controlled for conference changes, strength of schedule changes, the recruiting talent of former coaches, and regression to the mean, the Year-Two Effect remained a significant and more positive predictor of performance than the other seasons.

Shifting to the potential drivers of this phenomenon, the assumptions that recruiting, discipline, and consistency improve in a coach's second season were all tested using additional two-way fixed effects panel regression models. These results showed that, even while controlling for the prior performance of a program and whether or not it had moved to a new conference, recruiting tended to improve significantly in a coach's second season. Furthermore, while there was no evidence that the number of penalties committed per game was impacted by coaching tenure, teams led by second-year coaches generally committed fewer offensive turnovers per game compared to other seasons. As such, improved recruiting and a coach having had a full season to establish his schemes were both positioned as possible causes for the Year-Two Effect.

Nonetheless, the introduction of models that incorporated tenure variables based on the status of the programs when the coaches arrived showed that the effect is most pronounced in situations where the previous coach had been fired for performance-based reasons. Seeing as this likely came at a time when the team's performance measures (e.g., WIN\%) were low, it is not too surprising that the Year-Two Effect is most evident in these situations. With that being said, the results also revealed a significant decline in the season that immediately followed a prior coach taking a new job; a decline that disappeared during year two of a coach's tenure. Coaches also appeared to have a significant and positive impact in the second season after they had taken over for a retired coach, though this effect was no larger than a similarly-sized year-four effect. An additional model with a variable showing how much higher or lower a team's win percentage had been in the prior season compared to a 3 -year average of its win percentage revealed that a head coach's second season remained a significant sweet spot for improvement; however, the coefficient for the variable quantifying the Year-Two Effect was only marginally higher than the improvements that were seen moving into the third and fourth seasons. Therefore, while the Year-Two Effect may be quite evident throughout the FBS ranks, it is driven in large part by a regression to the mean.

\subsection{Practical Implications}

Having seen statistical evidence of the Year-Two Effect and what some of its potential causes may be, the question becomes, so what? Apart from lending credence to a popular media truism and shedding more light on its potential causes, what practical value can be gleaned from these discoveries? To begin, it is important to note how common coaching turnover is in the FBS ranks. Over 230 coaching changes occurred during the sampled timeframe, and the mean and median lengths of service were 5.87 and 4 seasons, respectively. Nearly $25 \%$ of the coaching changes in the sample involved coaches who either left or were removed from their posts following the fourth seasons of their tenure. The next closest percentages were the third and fifth seasons, at $14 \%$ and $13 \%$, respectively. This means that many coaches were not even making it to their first contract extensions, which commonly occur after or before the fifth season. The most common cause of them leaving their posts was being fired for performance reasons. Indeed, $59 \%$ of the head coaches in the sample took over for coaches who had resigned or been fired due to their team's inability to perform on the field. Coaches leaving for new jobs accounted for the next largest percentage $(26 \%)$, while retirements $(11 \%)$ and firings for non-performance reasons $(4 \%)$ rounded out the remainder.

Therefore, seeing as coaches will frequently be coming into situations where the Year-Two Effect is highly applicable, these results should help administrators and fans gauge their expectations accordingly; that is, quick improvements should be expected if the program is currently experiencing a lack of success on the field, with year-two improvement, in particular, being positioned as an attainable benchmark. Conversely, if a team is entering a season with a new coach after its former coach left the program for a 
new job, more leniency and grace should be given. Even so, the struggles should subside, or in the least level out, as the coach enters his second season. On average, a program is expected to improve during a head coach's second, third, and fourth seasons at the helm. These implications could also bleed through to athletic departments' marketing, sales, and fundraising teams, as they play an active role in developing initiatives that appropriately manage the expectations of their fan bases.

Furthermore, this study showed that coaches who are good recruiters should be pursued if a quick turnaround is desired. While recruiting struggles can be expected in the first season as potential signees remain wary of the uncertainty surrounding the program, the class that follows should help improve the team's talent level. A team's offensive turnovers should also decline as its coaching staff gets the proper personnel, systems, and schemes in place during the second season. In this regard, it might be normal to expect growing pains to occur in the first season as coaches and players are immersed in the new system; however, once year two rolls around, the on-field chemistry and consistency should improve.

These findings also raise some good talking points in regards to the structuring of head coaching contracts and the lucrative bonuses and buyout clauses that are now being included in them. If improvement is expected or anticipated in year-two, should it actually be rewarded in the form of a performance-related bonus? Would fewer coaches burn out at the three and four-year marks if improvements beyond years one and two were more highly incentivized? Questions such as these are important for athletic administrators to consider as they piece together multi-million dollar contracts in hopes of luring winning coaches to a program. If this study provided any guidance in this area, it would be to take context into account and structure deals around expectations that are relevant to the situation the coach is entering into. Its results would further suggest that initial contracts and buyout clauses should seldom extend beyond year four, since improvements were rarer from the fifth season onward and many coaches ended up being fired before then. Furthermore, it may be advisable for programs to insert escalating or de-escalating clauses based on whether or not the Year-Two Effect occurred. This might be particularly appealing to Group of Five programs that could insert escalating bonuses or buyouts if a coach is on schedule with his success, therefore making it harder for him to be lured away by institutions that are more presti- gious. Ultimately, though, more research is needed to determine whether coaches who achieve secondseason success actually end up leading their programs to success in the long run. Until then, it is likely that the market demand for college football success will continue to see head coaches on the receiving end of contracts and clauses that work in their favor. As such, it is important for future studies to continue exploring the relationships between coaching, talent, and performance.

\subsection{Limitations and recommendations for future research}

While this study takes an important first step in validating the existence of the Year-Two Effect for head coaches in the FBS, and what some of its key drivers may be, there are certainly further directions in which future studies could proceed. For starters, researchers could explore the Year-Two Effect in collegiate and professional sports outside of NCAA Division I football. Doing so might allow for its existence and its causes to be established as commonalities in the broader realm of coaching, rather than a phenomenon that is simply unique to college football. In addition, future studies could take a closer look at the second season and whether or not it holds any implications for the future; that is, does a successful second season serve as a barometer of sorts for future performance? Such findings could certainly help those in charge of coaching contracts make more informed decisions.

Continuing, it might also be interesting to develop predictive models that do and do not include a yeartwo coaching variable and compare their results for predictive purposes. While some of the predictor variables that would be included in these models likely display collinearities with coaching tenure, the outcomes would still be worth exploring for the implications they might hold for sports gamblers, athletic administrators, and others who could benefit from improved year-to-year projections. Lastly, additional coach-specific variables could be included to better model the situations that a program's coaches come from, rather than just those that they entered into. Indeed, one of the limitations of this study was that it did not signify the type of program a coach arrived from, what his history of success was, if he was running a similar scheme to the previous coach, or whether he had previously been serving with the team as a coordinator, assistant, or alumni. Future analyses could collect data on these variables and test them 
for their relationship to the Year-Two Effect and team performance in general.

\section{Notes}

1. The availability heuristic is the phenomenon whereby the more memorable something is (i.e., the easier it is to recall a specific event), the more likely people are to accept it as truth and assume it will happen again. In this case, the Year-Two Effect might be receiving errant reinforcement due to the fact that it has been witnessed among traditionally successful coaches at some of the more notable and historically successful Division I football programs.

2. Insufficient recruiting data and/or the lack of a team being present in a Power Five or Group of Five conference for the duration of the panel (2007-2017) were means for removal from the sample. In total, 16 current FBS programs (Appalachian State, Charlotte, Coastal Carolina, Florida Atlantic, Florida International, Georgia Southern, Georgia State, Massachusetts, Old Dominion, South Alabama, Texas State, UAB, UTEP, UTSA, Western Kentucky, and Troy) were excluded from the analysis based on these criteria.

3. For a more detailed explanation of this variable and how it is calculated, visit the following URL: ]urlhttps://www.sportsreference.com/blog/2015/03/srs-

calculation-details/https://www.sportsreference.com/blog/2015/03/srs-calculationdetails/.

4. Across all observations, these variables serve as proxies for the changes in talent level of the upperclassmen during the observed season. Whether this talent was brought in by a current or former coach depends on the observed coach's tenure. In situations where a coach is in his first or second season, the talent brought in by a former coach is being controlled for.

5. The coefficients for improvement are actually negative in this model since teams with lower national recruiting rankings are recruiting better talent (i.e., the team with the best recruiting class for a given season will have a rank of 1 , while the worst will be in the hundreds).

6. The data for the replacement variables were collected by consulting historical archives and press releases on official school webpages and media sites.

\section{Acknowledgments}

The authors would like to thank Brandon Mulkey for his help in conceptualizing this idea.

\section{References}

Bergman, S.A., \& Logan, T.D., 2016, The effect of recruit quality on college football team performance, Journal of Sports Economics, 17(6), 578-600.

Bird, M., 2017, Conference realignment is one reason the big 12 has fallen behind in recruiting, SBNation. https://www.sbnation.com/college-footballrecruiting/2017/2/8/14510684/big-12-realignmentrecruiting-rankings [Accessed 1 May 2018].

Caro, C.A., 2012, College football success: The relationship between recruiting and winning, International Journal of Sports Science \& Coaching, 7(1), 139-152.

Colbert, G.J., \& Eckard, E.W., 2015, Do colleges get what they pay for? Evidence on football coach pay and team performance, Journal of Sports Economics, 16(4), 335-352.

Connelly, B., 2016, College football teams tend to improve in a new coach's second year. But not after that, SBNation. https://www.sbnation.com/collegefootball/2016/12/27/14088090/new-college-footballcoaches [Accessed May 1 2018].

Dohrn, S., Lopez, Y.P., \& Reinhardt, G., 2015, Leadership succession and performance: An application to college football, Journal of Sport Management, 29(1), 76-92.

Emerson, S., 2017, The year 2 effect: Why kirby smart hopes history repeats itself, Dawgnation.com. https://www.dawgnation.com/football/year-2-kirby-smarthistory-repeats-itself [Accessed 1 May 2018].

Fogarty, K., Soebbing, B.P., \& Agyemang, K.J.A., 2015, NCAA division I-FBS salary determinants: A look at new and amended contracts, Journal of Issues in Intercollegiate Athletics, 8, 123-138.

Fulks, D.L., 2016, NCAA Revenues/Expenses Division I Report 2004-2015. Indianapolis, IN: NCAA.

Grant, R.R., Leadley, J.C., \& Zygmont, Z.X., 2013, Just win baby? Determinants of NCAA football bowl subdivision coaching compensation, International Journal of Sport Finance, 8(1), 61-74.

Herda, T.J., Ryan, E.D., DeFreitas, J.M., Costa, P.B., Walter, A.A., Hoge, K.M., Weir, J.P., \& Cramer, J.T., 2009, Can recruiting rankings predict the success of NCAA division I football teams? An examination of the relationships among rivals and scouts recruiting rankings and jeff sagarin end-of-season ratings in collegiate football, Journal of Quantitative Analysis in Sports, 5(4), Article 4.

Hoffer, A., \& Pincin, J.A., 2016, The effects of revenue changes on NCAA athletic departments' expenditures. Journal of Sport and Social Issues, 40, 82-102.

Hokanson, J., 2008, College football: What's with the second year coaching success? Bleacher Report. http://bleacherreport.com/articles/77720-college-footballwhats-with-the-second-year-coaching-success [Accessed 1 May 2018]. 
Holmes, P., 2011, Win or go home: Why college football coaches get fired, Journal of Sports Economics, 12(2), 157-178.

Huml, M.R., Pifer, N.D., Towle, C., \& Rode, C.R., 2019, If we built it, will they come? The effect of new athletic facilities on recruiting rankings for Power Five men's football and basketball programs, Journal of Marketing for Higher Education, 29(1), 1-18.

Kirshner, A., 2018, The SEC is paying out a record \$40.9 million per school, and the big ten could pass it soon, SBNation. https://www.sbnation.com/collegefootball/2018/2/2/16964186/sec-revenue-distribution-2017 [Accessed 1 May 2018].
Maxcy, J.G., 2013, Efficiency and managerial performance in FBS college football: To the employment and succession decisions, which matters the most, coaching or recruiting? Journal of Sports Economics, 14(4), 368-388.

Park, H.M., 2011, Practical guides to panel data modeling: A step by step analysis using stata. Public Management and Policy Analysis Program, Graduate School of International Relations, International University of Japan.

Torres-Reyna, O., 2010, Getting Started in Fixed/Random Effects Models Using $R$. https://dss.princeton.edu/ training/Panel101.pdf [Accessed 1 May 2018]. 